\title{
GRADUAÇÃO EM QUÍMICA: AVALIAÇÃO, PERSPECTIVAS E DESAFIOS
}

César Zucco

Departamento de Química, Universidade Federal de Santa Catarina, CP 476, 88040-900 Florianópolis - SC, Brasil

\begin{abstract}
THE UNDERGRADUATION IN CHEMISTRY: EVALUATION, PERSPECTIVES AND CHALLENGES. Poor standards in schools and the increase in the number of institutions of higher education - frequently without the due control - have adversely affected the quality of university level education in Brazil. On the other hand, evaluation of undergraduate courses, which has been carried out regularly since the min 1990's allow, within certain limits, a description of the quality Brazilian higher education courses in general, and Chemistry courses in specific. This paper evaluates the results of the national examinations (2000 and 2003's ENC, and 2005's ENADE), attrition rates for the 1990's and for the 2000-2005 period, as well as the perceptions of students and instructors that took part in those exams. Furthermore, the paper also analyzes the opinions of academics and of private sector professionals about the educational system's capacity to meet the job market's demand for skilled labor force. The actual profile of Chemistry graduates is then compared to what is demanded from them by the market, revealing deficiencies in the educational system. The expected essential curricula changes that would introduce an innovative and advanced approach in the undergraduate courses have become great challenges. In this sense, the paper seeks to reflect on questions such as: How to give informative courses a formative emphasis? Which programs should be included in the curricula to involve students in activities that require initiative and decision-making, thus fostering both learning and interest in Chemistry? How to prepare instructors for schools and for higher education? How to increase instruction in related areas without expanding the curricula excessively? How to introduce entrepreneurship in the curricula and further awareness of the professional non-academic careers in the area?
\end{abstract}

Keywords: undergraduation in Chemistry; evaluation; challenges.

\section{HISTÓRICO}

Desde a sua criação, em 1977, a SBQ tem se voltado para o avanço da Química, em especial das pesquisas inovadoras e de desenvolvimento ${ }^{1}$. Mais adiante, a partir do início da década passada, a instituição ampliou o leque de suas ingerências e vem patrocinando, também, a discussão sobre a formação do Químico nos níveis de graduação e pós-graduação. Como conseqüência dessa nova vertente, diversos artigos foram gerados e publicados pela Química Nova, dentre os quais se destaca o documento Eixos Mobilizadores em Química², em 2003, e, posteriormente, como seu desdobramento, um segundo documento, em 2004, A Formação do Químico ${ }^{3}$, cuja meta era despertar a discussão nas IES, regionais da SBQ e na reunião específica desta Sociedade para preparar a consolidação de uma doutrina sobre o tema.

Dentre os seis eixos mobilizadores apontados, quatro têm relação direta com a formação do Químico: i) a formação de recursos humanos qualificados, ii) o estímulo ao empreendedorismo e à interdisciplinaridade, iii) a desconcentração regional e o combate à endogenia, e iv) a aproximação pró-ativa da academia com a atividade econômica. Por isso, a SBQ continuou a incentivar a discussão sobre a formação de recursos humanos qualificados em todos os níveis. Assim, durante a 26a Reunião Anual da SBQ, em 2003, aconteceu o Simpósio A Formação do Químico $^{4}$, quando diversos debatedores, incluindo representante da Indústria Química, discutiram a formação - real e desejada - dos profissionais da Química, graduação e pós-graduação, as repercussões dessa formação no ensino (médio e superior) e a inserção desses profissionais no setor industrial.

Em outubro de 2004, em parceria com o Centro de Gestão e Estudos Estratégicos - CGEE, a SBQ promoveu o workshop Química no Brasil: perspectivas e necessidades para a próxima déca$d a^{5}$, visando analisar a atual configuração do processo de formação

*e-mail: czucco@qmc.ufsc.br e de organização da pesquisa na área da Química e sua adequação às perspectivas e necessidades para as atividades econômicas e para o delineamento de políticas sociais no Brasil. Novamente, um dos itens foi a formação do Químico: desafios e necessidades, comprovando-se que a formação de pessoal é uma das preocupações da SBQ, sobretudo quando se trata da Química como componente de desenvolvimento socioeconômico do país ${ }^{6}$.

Para melhor estruturar as ações voltadas para o ensino, a SBQ criou os Fóruns de Coordenadores de Cursos de Graduação em Química e de Coordenadores de Programas de Pós-Graduação em Química, que anualmente promovem o encontro de coordenadores para discussão de temas de interesse do ensino nesses dois níveis.

Há que se admitir que nos últimos anos, por força dos processos de avaliação institucional, empreendidos por iniciativa do MEC, o ensino superior brasileiro tem mostrado mudanças. $\mathrm{O}$ número de docentes doutores nas IES tem crescido com rapidez. As condições físicas, os laboratórios, as bibliotecas, as facilidades computacionais em quase todas as instituições estão se transformando para melhor. Porém, no que concerne à formação do graduado em Química, várias questões permanecem inalteradas, comprometendo, definitivamente, a sua formação. Se as discussões havidas no interior da SBQ servem para que se construa o perfil dos cursos de Química, a análise dos dados oficiais existentes sobre os cursos de graduação e os resultados das avaliações efetivadas a partir de 2000 apontam, ainda, para a falta de qualidade que permeia o ensino superior brasileiro e, por extensão, o ensino da graduação em Química.

Neste artigo será feita uma análise crítica dos resultados das avaliações realizadas, nos últimos anos, dos cursos de graduação em Química. Como toda avaliação tem por objetivo a busca da qualidade, nossa pretensão é, conhecendo as virtudes e as qualidades do sistema de avaliação, buscar qualificar o ensino de graduação em Química. Todavia, sabe-se que para dizer da qualidade de um curso, é necessário bem mais do que uma prova: faz-se necessária a ajuda de outros e diversificados instrumentos de avaliação e de in- 
formação, como, por exemplo, uma avaliação das condições de ensino e uma avaliação que coloque o foco na instituição. Portanto, além dos Exames Nacionais de Cursos, $\mathrm{ENC}_{\mathrm{s}}$ e do Exame Nacional de Desempenho Escolar, ENADE, serão abordados temas como evasão escolar, a percepção de professores e alunos nos diversos momentos avaliativos, manifestações de especialistas e de populares sobre o desempenho dos cursos de Graduação em Química.

\section{EVASÃo}

Recentemente, o Jornal Folha de São Paulo publicou ${ }^{7}$ resultados de pesquisas realizadas pelo Instituto Lobo ${ }^{8}$ para o Desenvolvimento da Educação, da Ciência e da Tecnologia, que indicavam que "metade dos universitários brasileiros não se forma. O Brasil tem uma das maiores taxas de evasão no ensino superior do mundo. Esse índice é duplamente pior nas instituições privadas do que nas públicas”.

Uma das formas usada para estimar a evasão do ensino superior foi comparar o número de concluintes com o de ingressos quatro anos antes. Embora seja uma metodologia que deixa de considerar inúmeros fatores embutidos na evasão9 ${ }^{9}$ é, sem dúvida, simples, de pronta execução e oferece parâmetros muito próximos que os de outras metodologias ${ }^{10}$. Essa relação é chamada de taxa de titulação, que ficou em 51\% no Brasil, em 2005. A evasão foi, portanto, de $49 \%$, considerada muito alta quando comparada com países desenvolvidos ou em desenvolvimento ${ }^{7}$. No Japão é 7\% e no México $31 \%$.

Outra forma de avaliar a evasão é estimando-a anualmente. Nesse caso, leva-se em conta o número de estudantes que já estavam no sistema no ano anterior e o número de estudantes que permaneceram estudando no ano seguinte ${ }^{8}$. Seguindo-se esta metodologia, a evasão anual no Brasil, considerados os anos de 2001 a 2005 , variou de $21 \%$ a $24 \%$ e, na média, ficou em $22 \%$.

Aplicando-se ambas as metodologias à Química, chega-se aos seguintes resultados: considerando a taxa de titulação (relação entre o número de concluintes e o de ingressos quatro anos antes), numa série histórica de $10 \operatorname{anos}^{11}$ - 1996 a 2005 -, a evasão variou de 38\%, num determinado ano, a $62 \%$, em outro. A média dessa série histórica foi $46 \%$. Por outro lado, no período de 2001 a 2005, a evasão anual estimada $^{8}$ variou entre $20 \%$ e $24 \%$, com média de $21 \%$.

Em 1997, a SESu, a ANDIFES e a ABRUEM publicaram estudo sobre diplomação, retenção e evasão, nas IES públicas brasileiras $^{12}$, cuja metodologia, definida como de $F l u x o^{10}$, consistia em acompanhar os alunos ingressantes em determinado curso, em ano e semestre específicos, até o prazo máximo de integralização curricular do referido curso, de acordo com os prazos do então CFE. Foram utilizadas as gerações completas dos cursos, cujos prazos máximos de integralização expirassem, sucessivamente, nos semestres 92/2 a 94/2. As médias, em termos de Brasil, foram: diplomação $48 \%$, retenção $10 \%$ e evasão $42 \%$. Nas mesmas condições, as Ciências Exatas e da Terra apresentaram, respectivamente, 28\%, 13\% e 59\%. O Bacharelado em Química, 38\%, 30\% e 32\%; o Bacharelado/Licenciatura em Química, 33\%, $15 \%$ e $52 \%$ e a Licenciatura em Química, $16 \%, 9 \%$ e $75 \%$.

Do exposto, lê-se que os Cursos de Bacharelado em Química têm evasão menor que a média nacional e, significativamente, menor que a da grande área das Exatas. A Licenciatura, comprovadamente, tem evasão altíssima e empurra a média da evasão em Química para cima, quando tratada como área do conhecimento. Comparando-se a evasão média anual da Química, 21\%, com a da Matemática, 30\%, a da Física, $24 \%$ e a da Biologia e Bioquímica, $21 \%$, entende-se que a Química está um patamar abaixo, embora isso não sirva como consolo. Nossos resultados são ainda muito ruins.

As perdas para o sistema de ensino de graduação, causadas pela evasão, começam com a estrutura que é mantida ociosa, em decor- rência do número de alunos que não estão mais estudando. A situação socioeconômica dos estudantes, tida como vilã da história, deixou de ser o principal causador da evasão, segundo especialistas. O desestímulo com o curso ou a falta de conhecimento prévio sobre a carreira pretendida no momento do ingresso são os principais fatores da evasão. O desestímulo, em parte, também é causado pelo despreparo dos alunos ao término do ensino médio, demandando, portanto, que os cursos e/ou as instituições elaborem uma política de ensino que possa recuperar esses alunos! Ensino de qualidade e bons professores estimulariam os alunos (que se evadem) a continuarem estudando. "É surpreendente que a taxa de desistência não seja maior, já que muitos cursos têm a mesma característica do século 19 e não são atraentes para os jovens. São visões antigas de mundo, que oferecem pouco do ponto de vista de uma formação mais sólida. Hoje, nossas universidades oferecem, na verdade, apenas um ensino tecnológico metido a besta", disse Edson Nunes, presidente do $\mathrm{CNE}^{7}$. A escolha, não acertada da carreira, feita muito cedo pelo ingressante, leva-o, freqüentemente, a trocar de curso na mesma instituição, a fazer outra escolha em outra instituição ou, simplesmente, à evasão.

Há que se acrescentar que as estatísticas mostram ${ }^{6}$ que os estudantes de graduação em Química, na média, são oriundos da parcela da população menos preparada técnica e cientificamente, o que justifica as dificuldades que os cursos enfrentam para impor ensino de qualidade. E mesmo que, em termos gerais, o número de candidatos aos cursos de Química seja três vezes o número de vagas oferecidas pelas IES, sabe-se que, em geral, na maioria das instituições privadas, essa relação é menor (muitas vezes muito menor do que 1), não havendo, portanto, qualquer barreira classificatória para o ingresso nesses cursos.

\section{EXAMES NACIONAIS DE AVALIAÇÃO DE CURSOS (ENC E ENADE)}

Os cursos de graduação em Química participaram do Exame Nacional de Curso $^{13}$ (o Provão), ENC, versões de 2000 a 2003, e do Exame Nacional de Desempenho ${ }^{14}$, ENADE, em 2005. Do ENC deveriam participar todos os alunos em condições de concluir o curso naquele ano; do ENADE, todos os estudantes do primeiro ano que tivessem concluído, até primeiro de agosto, entre $7 \%$ e $22 \%$ (inclusive) da carga horária mínima do currículo do curso, e os estudantes, do último ano do curso que, até primeiro de agosto, tivessem concluído pelo menos $80 \%$ da carga horária mínima do currículo ou todo estudante que se encontrasse na condição de possível concluinte do respectivo ano letivo.

Esses exames têm o objetivo de avaliar a qualidade do ensino oferecido pelos Cursos de Química, por meio da verificação do domínio dos conhecimentos desejáveis ao graduando para o exercício da profissão e da cidadania, e de colher informações que permitam conhecer o perfil dos graduandos de Química. Possibilitam, ainda, subsidiar programas e políticas de melhoria da qualidade de ensino.

A Tabela 1 sintetiza os resultados das provas dos exames de Química, em termos gerais. Respeitadas as particularidades e os aspectos positivos e negativos das três modalidades de cursos (Licenciatura, Bacharelado e Bacharelado com Atribuições Tecnológicas), a média das edições do exame, com exceção à de 2000, é praticamente idêntica, o que demonstra ausência de melhora. Na verdade, há que se ressaltar que a média 36 a 37 é muito baixa, considerando-se o máximo de 100 pontos. Obviamente, há concluintes que atingiram notas razoáveis, mas um número muito maior pouco pontuou. Outra constatação é que o número de alunos presentes (considerando-se, em 2005, somente concluintes) também é praticamente constante. Isso significa que o potencial de concluintes dos cursos não está au- 
mentando, embora esse número possa carecer de confiança. Em 2005, a participação de ingressantes, conforme já caracterizado acima, teve avaliação em separado. Constata-se que a participação destes é proporcionalmente maior; todavia, em função da alta evasão registrada nos cursos de Química, quando chegarem à conclusão do curso, certamente, este número terá encolhido, aproximando-se do número dos atuais concluintes, mantida a conjuntura presente.

O desempenho dos concluintes ${ }^{14}$ só não foi superior ao dos ingressantes em "componente específico" do Bacharelado com Atribuições Tecnológicas das Faculdades, Escolas e Institutos Superiores, nos quais os concluintes atingiram 13,5, contra 17,4, dos ingressantes (para pensar!). Esta nota dos concluintes é a menor deste grupo dentre as organizações acadêmicas aqui consideradas. A média mais baixa entre os ingressantes ocorreu nos centros universitários $(17,2)$, enquanto os melhores desempenhos dos dois grupos verificaram-se nas universidades, com média de 34,2 (concluintes) e de 23,1 (ingressantes).

Avaliando-se os resultados no país, em todas as edições dos exames de cursos ${ }^{13,14}$, Tabela 2 , o conceito C (3, em 2005) foi o que mais prevaleceu: de $32 \%$ a $42 \%$. Os conceitos A e B, de 2000 a 2003, variaram entre $26 \%$ a $33 \%$. Em 2005 foram apenas $17 \%$. Os conceitos D e E ficaram entre $27 \%$ e $36 \%$. Ressalte-se o elevado número de cursos sem conceito (SC): em 2005, 65\%, contra um percentual menor do que $4 \%$ em todos os outros anos. Sem conceito são considerados os cursos que naquele ano não tiveram formandos e, no caso do ENADE, não tiveram ingressantes ou concluintes. Portanto, qualquer que seja a explicação, quase dois terços dos cursos de Química apresentaram problemas (sem ingressantes ou concluintes), em 2005, e por isso as estatísticas desse ano podem apresentar-se prejudicadas em relação aos anos anteriores. A análise dos resultados gerais dos exames, todavia, aponta para um índice de aproveitamento, no mínimo, sofrível: apenas um terço dos cursos receberam conceitos A e B. Considerando-se que a média geral dos examinados foi 36 sobre 100, bastante baixa, os cursos com conceito C (ou 3), e menores, estão abaixo do aproveitamento mínimo desejável.

Cabe, inicialmente, esclarecer que, na Tabela 2, o curso (N) é usado como sinônimo de modalidade. Dessa forma, significa que a Licenciatura, o Bacharelado e o Bacharelado com Atribuições Tecnológicas são considerados como cursos, independentemente de como estão agrupados nas instituições, ou seja, um curso com duas ou mais "habilitações" (Licenciatura, Bacharelado ou Bacharelado com Atribuições Tecnológicas). O aumento dos cursos no espaço temporal de 2000 a 2005 é relativamente pequeno. Deve-se notar que em 2005, apesar de estarem computados 188 cursos, de fato, foram avaliados, ou receberam conceito, apenas 123, menos cursos que em 2003. Estes são os cursos que estão contribuindo para a formação de químicos. Nos anos 2000 a 2002, as instituições federais detinham $32 \%$ dos cursos, as estaduais em torno de 26 e as privadas 38\%. Em 2003 esses percentuais começaram a se alterar e, em 2005 , as privadas detinham $46 \%$, as estaduais $26 \%$ e as federais $23 \%$, evidenciando-se, pois, o crescimento do ensino privado.

A distribuição dos conceitos, nos anos de 2000 a 2003, por categoria administrativa, traz as instituições federais com praticamente $50 \%$ de seus cursos com conceitos A e B, seguidas das estaduais com um índice um pouco menor e as instituições privadas com um percentual médio de $10 \%$. O conceito $\mathrm{C}$ foi atribuído a mais de $30 \%$ dos cursos das federais, a $25 \%$ dos cursos das estaduais e a $32 \%$ a $42 \%$ dos cursos das privadas. Os conceitos D e E predominavam nos cursos das privadas, seguidas das estaduais. Em 2005, o número de cursos com conceitos A e B foi muito menor que nos anos anteriores, mas $34 \%$ dos cursos das federais mantiveram-se, ainda, nesse nível, seguidos de $16 \%$ dos cursos das estaduais e $11 \%$ das privadas. $\mathrm{O}$ conceito $\mathrm{C}$ distribuiu-se de forma análoga pelos três tipos de instituições. Os conceitos D e E predominaram nas privadas. Novamente, vale ressaltar que o número de cursos SC destoa dos anos anteriores e constitui $67 \%$ dos cursos das instituições municipais, $47 \%$ das estaduais, $32 \%$ das privadas e $20 \%$ das federais.

Contudo, várias inferências já foram feitas a respeito do desempenho dos cursos nesses exames:

1) Normalmente se pensa não haver comparabilidade entre os conceitos ano a ano, pois, em geral, o conceito A, em um ano, pode exigir um número de pontos bem distinto do A no ano seguinte.

2) Os desempenhos médios dos alunos, da mesma forma, também não são considerados comparáveis entre si, ocorrendo, por vezes, grandes discrepâncias de um ano a outro. Isso aconteceria porque as provas não têm por objetivo verificar se os alunos atingem ou não patamares pré-estabelecidos de qualidade; portanto, a comparabilidade estaria prejudicada por uma drástica alteração no nível de dificuldade da prova de um ano para o outro.

3) Que os conceitos não refletem a qualidade dos cursos e são inadequados para orientar políticas educacionais comuns a todos; são insuficientes para orientar os alunos, pais de alunos e a sociedade em geral sobre a qualidade dos cursos; são incapazes de adequadamente orientar as ações administrativas dos dirigentes das IES; e, também, são insuficientes para ranquear os cursos ou orientar políticas premiativas e/ou punitivas como se pretende/pretendia fazer.

É, também, discutível considerar meritório o ranqueamento de cursos, com base apenas no desempenho dos alunos concluintes numa prova, pois ao contrário do que se imagina, não é possível afirmar que a qualidade do desempenho dos alunos numa prova seja igual à qualidade de um curso. Um conceito baixo no ENC pode significar, por exemplo, que o curso recebe alunos muito fracos e que, apesar dos esforços institucionais, não é possível levá-los a um desempenho comparável aos dos alunos mais fortes de instituições com vestibulares altamente competitivos. Um "A", da mesma forma, pode significar simplesmente que, em função do alto nível de exigência de in-

Tabela 1. Estatísticas Gerais dos ENC-00-01-02-03 e ENADE-05 ${ }^{13,14}$

\begin{tabular}{|c|c|c|c|c|c|}
\hline Ano & 2000 & 2001 & 2002 & 2003 & 2005 \\
\hline Número de presentes & 3.236 & 3.168 & 3.222 & 4.038 & $7.072(3.952 \mathrm{I} \text { e } 3.120 \mathrm{C})^{2}$ \\
\hline Média & 27,4 & 36,8 & 37,1 & 37,0 & $31,8(28,9$ I e $36,1 \mathrm{C})$ \\
\hline Desvio-padrão & 12,8 & 13,3 & 13,1 & 12,5 & $13,0(11,6$ I e 13,9 C) \\
\hline Nota Mínima & 0,0 & 3,1 & 0,0 & 0,0 & 0,0 \\
\hline Mediana $^{1}$ & 24,4 & 36,3 & 36,2 & 36,5 & $31,1(28,5$ I e $36,0 \mathrm{C})$ \\
\hline Nota Máxima & 87,5 & 85,3 & 91,3 & 94,8 & $86,8(69,3$ I e 86,8 C) \\
\hline
\end{tabular}

${ }^{1}$ Medida de tendência central que divide a distribuição em duas partes iguais, i.e., é o ponto acima e abaixo do qual se situam $50 \%$ das notas; ${ }^{2}$ Ingressantes e Concluintes 
Tabela 2. Número de cursos (N) nos ENC-00-01-02-03 e ENADE-05 de Química e conceito obtido por categoria administrativa ${ }^{13,14}$

\begin{tabular}{|c|c|c|c|c|c|c|c|c|c|c|}
\hline & & & & Cate & oria Ad & & & & & \\
\hline Ano & Conceito & & eral & & dual & $\mathrm{Mu}$ & cipal & & rada & Brasil \\
\hline & & $\mathrm{N}$ & $\%$ & $\mathrm{~N}$ & $\%$ & $\mathrm{~N}$ & $\%$ & $\mathrm{~N}$ & $\%$ & $\mathrm{~N}(\%)$ \\
\hline 2000 & A & 10 & 29,4 & 3 & 10,7 & 0 & 0,0 & 0 & 0,0 & 13 (11.9) \\
\hline & $\mathrm{B}$ & 9 & 26,5 & 6 & 21,4 & 1 & 20,0 & 3 & 7,1 & $19(17,4)$ \\
\hline & $\mathrm{C}$ & 13 & 38,2 & 8 & 28,6 & 2 & 40,0 & 19 & 45,2 & $42(38,5)$ \\
\hline & $\mathrm{D}$ & 2 & 5,9 & 5 & 17,9 & 1 & 20,0 & 12 & 28,6 & $20(18,3)$ \\
\hline & $\mathrm{E}$ & 0 & 0,0 & 4 & 14,3 & 1 & 20,0 & 6 & 14,3 & $11(10,1)$ \\
\hline & $\mathrm{SC}$ & 0 & 0,0 & 2 & 7,1 & 0 & 0,0 & 2 & 4,8 & $4(3,7)$ \\
\hline & Total & 34 & 100,0 & 28 & 100,0 & 5 & 100,0 & 42 & 100,0 & $109(100,0)$ \\
\hline 2001 & A & 12 & 31,6 & 6 & 19,4 & 0 & 0,0 & 2 & 4,7 & $20(17,7)$ \\
\hline & $\mathrm{B}$ & 5 & 13,2 & 3 & 9,7 & 0 & 0,0 & 1 & 2,3 & $9(8,0)$ \\
\hline & $\mathrm{C}$ & 13 & 34,2 & 11 & 35,5 & 1 & 100,0 & 17 & 39,5 & $42(37,2)$ \\
\hline & $\mathrm{D}$ & 6 & 15,8 & 5 & 16,1 & 0 & 0,0 & 16 & 37,2 & $27(23,9)$ \\
\hline & $\mathrm{E}$ & 2 & 5,3 & 6 & 19,4 & 0 & 0,0 & 6 & 14,0 & $14(12,4)$ \\
\hline & $\mathrm{SC}$ & 0 & 0,0 & 0 & 0,0 & 0 & 0,0 & 1 & 2,3 & $1(0,8)$ \\
\hline & Total & 38 & 100,0 & 31 & 100,0 & 1 & 100,0 & 43 & 100,0 & $113(100,0)$ \\
\hline 2002 & A & 11 & 29,7 & 8 & 29,6 & 0 & 0,0 & 4 & 7,8 & $23(19,8)$ \\
\hline & B & 8 & 21,6 & 5 & 18,5 & 0 & 0,0 & 3 & 5,9 & $16(13,8)$ \\
\hline & $\mathrm{C}$ & 12 & 32,4 & 5 & 18,5 & 0 & 0,0 & 15 & 29,4 & $32(27,6)$ \\
\hline & $\mathrm{D}$ & 3 & 8,1 & 3 & 11,1 & 1 & 100,0 & 19 & 37,3 & $26(22,4)$ \\
\hline & $\mathrm{E}$ & 3 & 8,1 & 3 & 11,1 & 0 & 0,0 & 10 & 19,6 & $16(13,8)$ \\
\hline & $\mathrm{SC}$ & 0 & 0,0 & 3 & 11,1 & 0 & 0,0 & 0 & 0,0 & $3(2,6)$ \\
\hline & Total & 37 & 100,0 & 27 & 100,0 & 1 & 100,0 & 51 & 100,0 & $116(100,0)$ \\
\hline 2003 & A & 10 & 27 & 7 & 21,2 & 0 & 0,0 & 4 & 6,8 & $21(15,9)$ \\
\hline & B & 6 & 16,2 & 4 & 12,1 & 0 & 0,0 & 3 & 5,1 & $13(9,9)$ \\
\hline & $\mathrm{C}$ & 15 & 40,5 & 11 & 33,3 & 0 & 0,0 & 33 & 55,9 & $59(44,7)$ \\
\hline & $\mathrm{D}$ & 4 & 10,8 & 1 & 3,0 & 2 & 66,7 & 10 & 16,9 & $17(12,9)$ \\
\hline & $\mathrm{E}$ & 2 & 5,4 & 9 & 27,3 & 1 & 33,3 & 6 & 10,2 & $18(13,6)$ \\
\hline & $\mathrm{SC}$ & 0 & 0,0 & 1 & 3,0 & 0 & 0,0 & 3 & 5,1 & $4(3,0)$ \\
\hline & Total & 37 & 100,0 & 33 & 100,0 & 3 & 100,0 & 59 & 100,0 & $132(100,0)$ \\
\hline 2005 & 1 & 0 & 0,0 & 0 & 0,0 & 0 & 0,0 & 1 & 1,2 & $1(0,5)$ \\
\hline & 2 & 3 & 6,8 & 4 & 8,2 & 3 & 33,3 & 16 & 18,6 & $26(13,8)$ \\
\hline & 3 & 17 & 38,6 & 14 & 28,7 & 0 & 0,0 & 32 & 37,2 & $63(33,5)$ \\
\hline & 4 & 12 & 27,3 & 7 & 14,2 & 0 & 0,0 & 9 & 10,5 & $28(14,8)$ \\
\hline & 5 & 3 & 6,8 & 1 & 2,0 & 0 & 0,0 & 1 & 1,2 & $5(2,7)$ \\
\hline & $\mathrm{SC}$ & 9 & 20,6 & 23 & 46,9 & 6 & 66,7 & 27 & 31,3 & $65(34,7)$ \\
\hline & Total & 44 & 100,0 & 49 & 100,0 & 9 & 100,0 & 86 & 100,0 & $188(100,0)$ \\
\hline
\end{tabular}

gresso, o curso está trabalhando com os melhores alunos. Da mesma forma, o resultado desses exames depende, ainda, do nível de empenho e interesse dos alunos ao realizá-lo. Neste caso, o desempenho no ENC pode ter muito pouco a ver com a titulação dos professores, a sofisticação das metodologias e técnicas de ensino, a quantidade e atualidade do acervo bibliográfico, a qualidade de laboratórios didáticos ou a atmosfera acadêmica do curso, etc.

Portanto, reitera-se que, para qualificar-se um curso, é necessário muito mais do que uma prova; necessita-se, no mínimo, de um conjunto diversificado de instrumentos e de informações sobre o curso, sobre o aluno e sobre a instituição.

\section{PERCEPÇÃO DOS ESTUDANTES DE QUÍMICA: RESPOSTAS AO QUESTIONÁRIO}

A análise das informações contidas no questionário submetido aos participantes ${ }^{14}$ do ENADE-05 permite a construção do seguinte perfil: os graduandos dos cursos de Química são, em sua maioria, $52 \%$, do sexo feminino, $40 \%$ com idade até 24 anos e $36 \%$ entre 25 e 29 anos, com média de 27 anos. Os ingressantes têm idade média de 23,1 anos. Vinte e nove por cento declararam que suas famílias têm renda de até 3 salários mínimos, enquanto $57 \%$ têm entre 3 e 10 salários. Apenas $21 \%$ não exercem atividade remunerada para sustento próprio; $28 \%$ trabalham e, ainda assim, necessitam da ajuda familiar; $18 \%$ se sustentam com o próprio trabalho; $23 \%$ trabalham e contribuem para o sustento familiar; e outros $9,3 \%$ são responsáveis pelo principal sustento da família. Mais de $60 \%$ desses estudantes usam o transporte coletivo, enquanto $20 \%$ têm moto ou carro.

O questionário dá oportunidade a que algumas questões do ENC de 2000 sejam comparadas a questões similares do ENADE-05 (cinco anos após, portanto), contribuindo para o possível entendimento do desempenho desses estudantes, conforme discussão adiante.

O grau de dificuldade do componente específico da prova foi e continua sendo considerado mais difícil que o componente geral, tanto nas questões objetivas quanto nas discursivas. A forma de abordagem dos conteúdos pelas questões da prova nacional foi considerada diferente daquela adotada pelos cursos, tendo sido apontada por $35 \%$ dos participantes da prova como um fator de dificuldade; outro tanto declarou que o desempenho foi limitado porque, apesar de haver estudado os conteúdos, não os aprendeu, repetindose, pois, a justificativa dada em 2000. Estudaram em escolas médias públicas, especialmente nas estaduais, $58 \%$ dos concluintes, en- 
quanto $27 \%$ são oriundos de escolas privadas, percentuais idênticos a 2000. Em 2005, 92\% disseram ter acesso à internet (77\% nas IES e $63 \%$ também em casa); em 2000, $40 \%$ acessavam via IES, $25 \%$ de casa e $20 \%$ de outros ambientes, todavia, $60 \%$ tinham alguma limitação quanto ao acesso a computador. A TV continua sendo o veículo mais usado para manter-se atualizado, $60 \%$ em 2005 , contra 54\% em 2000. A internet vem em segundo plano, com $27 \%$ eram $10 \%$ - acompanhada de jornais, revistas e rádio, praticamente, com os mesmos percentuais de 2000. O hábito para o estudo, medido em horas de estudos por dia, é baixo e em nada mudou de 2000 para 2005: 6,3\% disseram que não estudavam, apenas assistiam às aulas; $34 \%$ estudavam até 2 horas, enquanto outros $34 \%$ estudavam de 3 a 5 horas. Apenas 13\% despendiam de 6 a 8 horas e outros $13 \%$ mais do que 8 horas diárias.

É importante ressaltar que o ENADE-05 mostrou, ainda, que a inserção dos alunos em atividades extra-classe está muito aquém do desejável: apenas $8,4 \%$ dos concluintes desenvolveram atividades de monitoria; $14 \%$ participaram em projetos de pesquisa coordenados por docentes; $23 \%$ exerceram atividades de iniciação científica ou tecnológica e $45 \%$ não participaram dessas atividades (índice idêntico a 2000). Tratando-se, especificamente, de projetos de iniciação científica, o quadro fica mais desabonador: $28 \%$ fizeram parte de projetos de pesquisa supervisionados por professores, alguns alunos disseram ter desenvolvido pesquisa independente (sozinhos), outros participaram de projetos de professores e de pósgraduandos, mas, 55\% nunca participaram de qualquer pesquisa, por desinteresse ou por falta de oportunidade.

\section{ANÁLISE CRÍTICA DOS RESULTADOS DOS PROCESSOS AVALIATIVOS}

Já foi dito, em outras oportunidades, que é voz corrente que os químicos formados em várias IES públicas e privadas do país têm nível de conhecimento compatível com o de seus colegas de países desenvolvidos. Isso significa, simplesmente, que há um reconhecimento internacional e, especialmente, latino-americano, de que várias instituições no Brasil estão formando bons químicos. Todavia, não se pode ignorar que mesmo esses centros de excelência formam, sob alguns aspectos, químicos despreparados.

Além dos resultados das avaliações em questão, a partir de discussões acadêmico-profissionais patrocinadas pela $\mathrm{SBQ}^{4}$, nos últimos anos, pode-se elencar diversas deficiências na formação dos químicos brasileiros: a) fraca formação em áreas afins à Química, por exemplo, Biotecnologia, Biologia e outras modalidades de conhecimento atuais e novas para os químicos; b) a maioria dos químicos é formada com orientação tipicamente voltada para uma pósgraduação como um fim em si mesma, quando esta deveria ser encarada como um meio de formação continuada, conseqüentemente para aumentar a capacidade criativa e empreendedora do candidato (70\% dos graduandos em Química querem fazer cursos avançados); c) desconhecimento da importância e da participação estratégica da Química na vida contemporânea; d) os estudantes gastam muito tempo com conteúdos de interesse restrito, ao invés de se ocuparem/aprenderem sobre as substâncias que são insumos do dia-a-dia das indústrias e estão presentes no cotidiano das pessoas (corantes, tensoativos, polímeros, compostos da indústria de base, especialidades da química fina); e) há desconhecimento do sistema econômico em que a Química é desenvolvida: empresas, produtos, processos e setores de aplicação e, pior, pouco se aprende, na graduação, sobre o exercício e a regulamentação da profissão do Químico; f) na maioria dos projetos didático-pedagógicos dos cursos de Química, a carga horária experimental é de apenas $30 \%$.

Com acertos e erros conceituais e metodológicos amplamente conhecidos e discutidos, os resultados das provas dos estudantes nos $\mathrm{ENC}_{\mathrm{s}}$ e ENADE permitem um mapeamento da qualidade curricular e didático-pedagógica dos cursos de Graduação no Brasil, entre eles os de Química. E essa análise não deixa dúvidas: nossos cursos de graduação em Química não estão oferecendo boa formação, mais de $60 \%$ deles obtiveram conceito igual ou menor do que $\mathrm{C}$ nas cinco edições do exame e, na média, $80 \%$ dos cursos das IES privadas estão nessas condições. Corrobora essa assertiva a média das provas ao longo dos anos (aproximadamente 36 sobre 100).

A evasão é outro problema que aflige o sistema de ensino superior. Mesmo considerando que a maioria dos alunos dos Cursos de Química precisa trabalhar para manter-se, esta não está entre as principais razões da evasão: os especialistas apontam a desmotivação do aluno e o desinteresse das instituições. Estas não se preocupam em oferecer um ensino atualizado (!) e atraente, além de não buscarem resolver a deficiência que os alunos trazem do ensino médio. Lembrando que a evasão ocorre, sobretudo no primeiro ano, Vincent Tinto $^{15}$, da Universidade de Syracuse, afirma que a frequiência e a qualidade da interação dos estudantes com os professores, funcionários e colegas é um dos principais indicadores não só da permanência, mas também do aproveitamento estudantil. Ainda, segundo o autor, o melhor programa de permanência é sempre um forte programa acadêmico que envolva ativamente os estudantes na aprendizagem, especialmente com os colegas e professores. A evasão é uma fonte de ociosidade de professores, funcionários, equipamentos e espaço físico. Portanto, para o país, a desistência do aluno representa perdas sociais e econômicas importantes. Do ponto de vista da instituição, não há maior fracasso no atendimento de sua missão do que o aluno que se evade ${ }^{8}$.

O elevado percentual de alunos concluintes, $55 \%$, que disse nunca ter participado de qualquer pesquisa, por desinteresse ou por falta de oportunidade, é o maior sintoma da falta de programas que envolvam ativamente os alunos em temas atraentes e formadores em Química. Mais de $45 \%$ também disseram que nunca participaram de atividades extra-classe (monitoria, programas de extensão, atividades culturais e comunitárias, etc.). A baixa inserção dos alunos da Química, especialmente em programas de iniciação científica, além de ser aspecto negativo e prejudicial à formação do químico, contraria as diretrizes curriculares, onde a prática da pesquisa é considerada essencial e deveria integrar o currículo de todo o alunado.

A internet já é acessada por mais de $90 \%$ dos estudantes de Química, nas suas IES ou em casa, e mais de 70\% disseram que a usam para pesquisar durante a realização dos trabalhos e estudos. Uma correlação mostrou que os alunos que usam com maior freqüência a internet são os que apresentaram desempenho superior no ENADE-05.

Vários outros aspectos merecem nossa atenção, dentre eles algumas afirmações feitas pela maioria dos estudantes de Química: i) dedicava menos de $10 \mathrm{~h}$ semanais para estudo extra-classe; ii) sabia muito pouco de inglês e de espanhol; iii) lia, em média, um livro por ano; iv) quase não lia jornais. Ainda assim, $40 \%$ deles afirmaram que pretendem trabalhar no ensino; $70 \%$ pensam fazer pósgraduação e mais de $80 \%$ querem trabalhar na área de Química.

\section{CONCLUSÕES E DESAFIOS}

O ensino de graduação em Química, mesmo contando com especificidades e características próprias, pouco se diferencia qualitativamente, das suas áreas afins, considerando-se os indicadores dos processos de avaliação, nos últimos cinco anos. Os resultados das avaliações mostram que os cursos, na maioria, estão aquém do nível de qualidade desejável e apontam para a necessidade de alterações e mudanças de rumo nos projetos didático-pedagógicos dos cursos. 
Espera-se que venham a oferecer, antes de tudo, uma formação sólida em Química, mas que seja abrangente e generalista o suficiente para que o Químico possa se desenvolver em mais de uma direção, conforme as futuras necessidades que enfrentar. As diretrizes curriculares dos Cursos de Química são, reconhecidamente, flexíveis a ponto de permitirem a implantação de currículos que possam atender as constantes mudanças do mundo globalizado. Porém, deixadas a sós, nada acontecerá no mundo acadêmico da graduação.

Os problemas que dificultam o oferecimento do ensino de qualidade aos graduandos devem ser discutidos pelos professores, alunos, administrações institucionais e segmentos da sociedade organizada, e os encaminhamentos resultantes devem ser abraçados por todos, indistintamente. Atos individualizados e isolados não serão suficientemente responsáveis para reverter a inércia que toma conta da maioria dos cursos.

A inclusão, nos currículos, de programas com orientação, mas que envolvam os alunos em atividades que exijam iniciativas e decisões próprias - por exemplo, iniciação científica e ou iniciação tecnológica - é uma das alternativas que mais desperta o interesse pela Química, elevando o nível da aprendizagem e reforçando os laços da permanência, e, naturalmente, afastando o mal da evasão.

A qualificação para a docência dos professores universitários e do ensino médio deve ser repensada. Geralmente, quando os egressos dos cursos de Química não encontram os espaços desejados, acabam optando, como alternativa profissional, pela docência. Aí surgem, então, a falta ou insuficiência de formação para ser professor. Segundo Maldaner, é diferente saber os conteúdos de Química, por exemplo, em um contexto de Química, de sabê-los, em um contexto de mediação pedagógica dentro do conhecimento químico ${ }^{16}$. As salas de aulas dos ensinos médio e superior não mudam porque os professores continuam sendo formados (!), ou aprendem a ser professores, observando seus professores (é a denominada" "formação ambiental"), e não por uma formação específica que deveria ocorrer em autênticos cursos de licenciatura. Por isso, as licenciaturas hoje devem se caracterizar como cursos autônomos e não apêndices de bacharelados. Porém, formar bem os professores não basta; é indispensável que suas capacitações sejam melhoradas a cada dia.

A formação profissional deve visar um graduado com intimidade em novas tecnologias, com sólido conhecimento em Química, mas com formação nas áreas afins à Química e com espírito empreendedor. A formação do pós-graduando deve também visar sua colocação na indústria.
O exercício da profissão de químico demanda, igualmente, encaminhamentos, dentre os quais a não-verticalização de suas atribuições, reconhecendo-se, nesse sentido, a pós-graduação como formação continuada e, portanto, de melhoria no exercício profissional.

O enfrentamento desses desafios permitirá construir o perfil do profissional de Química para o próximo qüinquiênio e, se perspicazes formos às correções de rumo que as mudanças nos impõem continuamente, então estaremos formando o Químico de que a sociedade necessita.

\section{REFERÊNCIAS}

1. de Andrade, J. B.; Pinto, A. C.; Cadore, S.; Vieira, P.C.; Zucco, C.; Pardini, V. L.; Curi, L. R. L.; Quim. Nova 2005, 28 (Supl.), S7.

2. de Andrade, J. B.; Cadore, S.; Vieira, P. C.; Zucco, C.; Pinto, A. C.; Quim. Nova 2003, 26, 445.

3. de Andrade, J. B.; Cadore, S.; Vieira, P. C.; Zucco, C.; Pinto, A. C.; Quim. Nova 2004, 27, 358

4. de Andrade, J. B.; Galembeck, F.; Gandur, M. C.; Livro de Resumos da $26^{a}$ Reunião Anual da Sociedade Brasileira de Química, Poços de Caldas, Brasil, 2003.

5. Workshop Química no Brasil: perspectivas e necessidades para a próxima década. Promoção do Centro de Gestão e Estudos Estratégicos, CGEE, e da Sociedade Brasileira de Química, SBQ, ocorrida na Sede do Conselho Regional de Química de São Paulo, em 27 e 28 de outubro de 2004.

6. Zucco, C.; Quim. Nova 2005, 28 (Supl.), S11.

7. Jornal Folha de São Paulo, Cotidiano, de 31 de dezembro de 2006

8. Silva Filho, R. L. L.; Lobo, M. B. de C. M.; Hipólito, O.; Evasão no ensino superior: causas e remédios, Instituto Lobo, disponível em: www.institutolobo.org.br/instituto, acessada em Janeiro 2007.

9. Não há dados que permitam acompanhar com precisão a trajetória de todos os alunos que entram no ensino superior em determinado ano. Por isso, a estimativa é feita levando em conta o tempo médio de conclusão de um curso, quatro anos. Se fosse considerado um intervalo maior, cinco anos, por exemplo, ainda assim a evasão seria alta e próxima à estimada. Cf. Folha de São Paulo, Cotidiano, 31 de dezembro de 2006.

10. Ramos, M. N.; Quadro da Evasão na UFPE: Metodologia, Causas e Ações, UFPE: Pernambuco, 1995

11. MEC-INEP; Censo do Ensino Superior do Brasil, disponível em: www.inep.gov.br, acessada em Janeiro 2007.

12. MEC-SESu; Diplomoção, Retenção e Evasão nos Cursos de Graduação em Instituições Federais de Ensino Superior Públicas, Estudo. 1997.

13. MEC-INEP; Relatórios-Síntese ENC-2000 a 2003. 4 CDs.

14. MEC-INEP; Relatório Síntese, ENADE-2005, disponível em: www.inep.gov.br, acessada em Janeiro 2007.

15. Tinto, V.; Engstrom, C.; Hallock, H.; Riemer, S.; Learning Communities in Higher Education, Higher Education in the United States: An Encyclopedia, ABC-CLIO Publishers: Santa Bárbara, 2001.

16. Maldaner, A. O., A formação inicial e continuada de professores de Química: professores pesquisadores,: Ed. UNIJUÍ: Ijuí, 2000. 